\title{
Article
}

\section{Examining the functions of prison critical incidents: a preliminary qualitative analysis of public reporting}

Hughes, Cameron, Ireland, Jane Louise and Ireland, Carol Ann Available at http://clok.uclan.ac.uk/21655/

Hughes, Cameron, Ireland, Jane Louise ORCID: 0000-0002-5117-5930 and Ireland, Carol Ann ORCID: 0000-0001-7310-2903 (2018) Examining the functions of prison critical incidents: a preliminary qualitative analysis of public reporting. Journal of Criminological Research Policy and Practice, 4 (2). pp. 101-110. ISSN 2056-3841

It is advisable to refer to the publisher's version if you intend to cite from the work. http://dx.doi.org/10.1108/JCRPP-12-2017-0040

For more information about UCLan's research in this area go to http://www.uclan.ac.uk/researchgroups/ and search for < name of research Group>.

For information about Research generally at UCLan please go to http://www.uclan.ac.uk/research/

All outputs in CLoK are protected by Intellectual Property Rights law, including Copyright law. Copyright, IPR and Moral Rights for the works on this site are retained by the individual authors and/or other copyright owners. Terms and conditions for use of this material are defined in the policies page.

\section{CLoK}

Central Lancashire online Knowledge www.clok.uclan.ac.uk

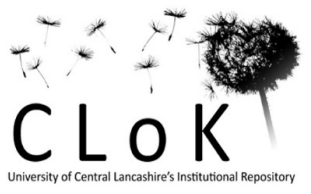


Examining the functions of prison crisis incidents: A preliminary qualitative analysis of public reporting

\author{
Cameron Hughes, Jane L. Ireland ${ }^{1 *}$, Carol A. Ireland* \\ University of Central Lancashire, Preston, UK; *and Ashworth Research Centre, Mersey \\ Care NHS Trust: UK.
}

${ }^{1}$ Corresponding author. Email: JLIreland1@uclan.ac.uk; University of Central Lancashire, Preston, UK, PR1 2HE; Tel: +44 1772201201. 


\begin{abstract}
Purpose: The current study explored the function of crisis incidents in prisons within the UK and US. The incidents reviewed included riots and hostage-incidents, focusing only on information that was available publically. It did not intend to capture official reports not in the public domain.
\end{abstract}

Design/methodology/approach: Publically available information on incidents were systematically reviewed. Functional assessment and grounded theory were employed to examine background factors, triggers and maintaining factors. Twenty-five crisis incidents were analysed $(\mathrm{UK}=10$ and $\mathrm{US}=15)$ from the past 30 years. It was predicted that crisis incidents would be motivated by negative and positive reinforcement, with negative more evidenced than positive. Precipitating factors (i.e. triggers) were predicted to include negative emotions, such as frustration and anger.

Findings: Similarities in triggers and background factors were noted between hostage taking and riot incidents. Positive reinforcement was primarily indicated. Riots appeared driven by a need to communicate, to secure power, rights, control and/or freedom whereas for hostage taking these functions extended to capture the removal of negative emotions, to inflict pain, to punish/gain revenge, to effect a release, to manage boredom, and to promote positive emotions.

Research limitations/implications: The study is preliminary and focused on the reporting of incidents in publically available sources; consequently, the data is secondary in nature and 
further limited by sample size. Nevertheless, it highlights evidence for similarities between types of crisis incidents but also some important potential differences. The need to understand the protective factors preventing incidents and minimising harm during incidents is recommended.

Originality/value: This is an under-researched area. The study contributes to the field not only by focusing on providing a detailed analysis of an under-used source (public reporting) but by also identifying where gaps in research remain. The results demonstrate the value in understanding incidents through their motivation, particularly in distinguishing between negative and positive reinforcement.

Keywords: Hostage taking; Riots; SORC; Public reporting; Prison aggression.

\section{Introduction}

Crisis incidents in secure settings includes riots, roof-top protests, barricades and hostage taking, thought usually triggered by a non-rational, over-emotional state (Vecchi, Van Hasselt \& Romano, 2005). During such a state, individuals feel unable to resolve their crisis, resulting in them using extreme problem-solving methods (Ireland, Halpin \& Ireland, 2015; Hatcher, Mohandie, Turner \& Gelles, 1998; McMains, 1993). However, our understanding as to why these incidents occur remains limited, particularly regarding the functions they serve (Cooke, Baldwin \& Howison, 1990; Ireland et al, 2015), including the role of the environment (Boin \& Rattray, 2004). This is a product of limited research.

Of the research that is available, the majority has focused on hostage incidents but even this has been limited, in part because of the accessibility of the data available owing to 
the sensitive nature of the topic. It is accepted, however, that crisis incidents occur in a variety of environments, including secure hospitals (Hatcher et al, 1998; Völlm, Bickle \& Gibbon, 2013) and prisons (Mailloux \& Serin, 2003). These environments restrict freedom (Ireland et al, 2015) and are more likely than non-secure environments to contain individuals capable of violence (Feldman, 2001; Mailloux \& Serin, 2003). In such settings, it is noted that hostage taking is perpetrated more by men than women (Mailloux \& Serin, 2003; Williams, 1995; Völlm et al, 2013); a likely product of more men than women being detained in secure settings. Regardless of placement in a prison or a secure hospital, in both environments, hostages are utilised to secure a gain/to facilitate a goal (Völlm et al, 2013; Mailloux \& Serin, 2003).

Overall, however, crisis incidents are a rare occurrence in secure settings (Hatcher et al, 1998; Phillips, 2011) but their impacts can be significant in relation to the physical and psychological harm caused to those involved (Mailloux \& Serin, 2003). For example, violence inflicted on hostages during incidents is potentially more common in highly emotive situations, such as those involving suicide attempts and/or occurring as part of domestic incidents (Yokota et al, 2004). Offender characteristics, such as mental illness and drug use, were also significant perpetrator aspects for inflicting violence upon hostages (Mailloux \& Serin, 2003), where low risk aspects included making demands for money, food, or ensuring a means to escape (Phillips, 2011). Hostage taking was also most commonly conducted by those with an anti-social personality disorder (Mailloux \& Serin, 2003; Williams, 1995), those with a prior history of violence (e.g. Furr, 1994), and/or those with a previous history of having taken hostages (Völlm et al, 2013).

Although, little empirical evidence exists regarding why such incidents occur, the differences between incident types and/or who is likely to conduct them, there is developing consensus that such incidents are motivated by perpetrators perceiving a likely 
gain (Hatcher et al, 1998). Considering such incidents as 'motiveless' does not apply (Yun \& Roth, 2008; Wilson \& Smith, 2000). Indeed, possible triggers suggested for hostage situations have included high levels of stress, anger, sexual frustration and feelings of injustice (Mailloux \& Serin, 2003; Cooke et al, 1990; Völlm et al, 2013), whereas others have also commented on the difficulties in identifying a trigger for some incidents (Völlm et al, 2013). This has been equally applied to understanding riots in prison, with Boin \& Rattray (2014) proposing a Threshold Model to explain why riots occur, indicating how they are a result of institutional breakdown alongside an administrative breakdown that erodes safety mechanisms. This model considers riots the product of declines in both administrative and institutional decline and thus more a product of failure in systems than considered simply an extreme end of poor behaviour by prisoners. However, the Threshold Model remains hypothesised and not yet supported by empirical evidence, which is characteristic of most theoretical propositions in the area of crisis management.

Research to date has also failed to explore in detail the functions (motivations) that such incidents can serve, with a focus solely on triggers and the wider organisational factors (Boin \& Rattray, 2014). At a basic level the motivation for any form of aggression can be driven by two broad forms of reinforcement; negative reinforcement (i.e. the removal of an unpleasant stimulus) and positive reinforcement (i.e. a gain/reward) (Ireland, 2018), but the applicability of such categories to crisis incidents have not been yet considered.

The current study aimed to address this area by exploring the triggers, background, and motivating factors indicated in public reporting (i.e. newspapers, online journals) of crisis incidents in secure settings. A systematic review of public reports from the UK and US was conducted. A functional assessment of the reported incidents and grounded theory was employed to identify themes. It was predicted that crisis incidents would be motivated 
by negative reinforcement (i.e. the need to remove unpleasant stimulus) and positive reinforcement (e.g. gains), and that incidents would be motivated more by negative than positive reinforcement (Verma, 2007). Precipitating factors (i.e. triggers) were predicted to include negative emotions, such as frustration and anger (Ireland et al, 2015; Feldman, 2001; Mailloux \& Serin, 2003; Verma, 2007).

Method

$\underline{\text { Review of public reports }}$

A systematic review was conducted using reports collected from public access websites. Four online data sources were used to obtain academic articles reporting on crisis incidents, namely Google Scholar, Web of Science, Science Direct and Psych.Info. Further reviewed sources included newspaper and public enquiry reports and book chapters. Relevant key search terms included: Crisis; Hostage; Rooftop Protest; Barricade; Riot; High Secure; Prison. Searching was limited to UK and US sources and to the past 30 years of reporting. In addition, to improve reliability, multiple sources of the same incident were reviewed, where possible. Due to the nature of the sources (e.g. newspaper articles), this also reduced likely sensationalism and/or reporting error that can appear in newspaper reports (LindsayBrisbin, DePrince \& Welton-Mitchel, 2014). This approach resulted in 30 crisis incidents in secure settings being reported in publically available documents. Of these, 25 had sufficient useable data to conduct an analysis on (10 UK, $15 \mathrm{US})$. 


\section{Analysing the reports}

A functional assessment and grounded theory approach was employed. Functional assessments are tools used to determine why behaviour has occurred, accounting for triggers and reinforcing factors (Ireland, 2018). The current study used the SORC functional assessment (Lee-Evans, 1994). This allows for an assessment of Stimuli (antecedents/triggers), Organism variables, Responses (behaviour) and Consequences (reinforcers). Such an approach has been previously applied to conducting analyses of newspaper reporting (Birch, Ozanne, Ireland, 2017). An individual SORC was completed for each crisis incident, where the triggers to events, background factors, nature of the event and negative and positive reinforcers post event were recorded, with the aim to identify the incident functions. SORCs essentially acted as data capture sheets in this instance. An example of a completed SORC is indicated in Figure 1.

\section{<<INSERT FIGURE 1 HERE $>$.}

Grounded Theory was applied to each completed SORC assessment. Grounded Theory is well recognised as a method for exploring, gathering and analysing qualitative data in order to produce conceptual categories. It allows for systematic engagement with the data through an iterative process (Schreiber \& Stern, 2001; Glaser \& Strauss, 1967). Here the SORC provided the generative questions to help guide the process, with the focus here on the identification of themes. Open coding was used, namely where the data was considered in considerable detail to initially develop themes before they were then coded in relation to the core concepts provided by the SORC. 


\section{Results}

\section{Number and type of crisis incidents}

The number and forms of incidents captured $(n=25)$ are presented in Table 1.

$<<$ INSERT TABLE 1 HERE $>>$

Table 1 demonstrates that hostage incidents were the most reported in public records, as opposed to other forms of crisis incidents, with barricades and rooftop protests not indicated. All hostage incidents were restricted to prison settings. The average hostage-incident time was 83 hours. The duration of UK riot incidents was not reported, with the only known duration of a US riot incident less than 1 hour. Five of the 19 hostage incidents involved the taking of multiple hostages.

\section{Hostage taking incidents}

\section{$\underline{\text { SORC and grounded analysis of incidents: Antecedent themes }}$}

Open coding was conducted to identify all themes. Five antecedent themes were identified: feeling wronged, feeling negative, having support from peers, having access to the victim, and present drug use. Each theme is presented here in rank order of frequency: 
Access to the victim focused on the method of access, with this theme appearing in $84 \%$ (16) of instances and including planning ahead of time, taking advantage of low staff numbers or an unexpected opportunity. Planning appeared in 10 of the instances.

Support from peers appeared in 79\% (15) of instances and included in all cases having co-peers to engage with.

Feeling negative was noted in 63\% (12) of instances and included feelings of anger, injustice, disrespect, disgust, violation, stress, depression, a need for revenge and boredom.

Feeling wronged appeared in $42 \%$ (8) of instances and included the death of another individual by authority, feeling that others must pay, feeling wronged in relation to religious beliefs not being attended to, feeling that others must be held to account and/or considering rights (e.g. privacy, available space) were being violated.

Present drug use appeared in one incident (5\% of all cases) and referred to being under the influence of a drug beforehand.

$\underline{\text { SORC and grounded analysis of incidents: Background (Organism) themes }}$

Again, open coding was employed. Background factors included five themes, namely supportive beliefs, distorted sense of justice, religion, stressful present environment, and past drug use. Regarding each theme, in rank order of frequency: 
Supportive beliefs appeared in all instances and included the belief that hostage taking was acceptable and that it was acceptable to use violence for a gain. These beliefs were evidenced in all reports. It also included the belief that hostages could be used to bargain with the authorities with and that those who upset them must be punished.

Stressful present environment was identified in all instances, specifically relating to residing in conditions of security.

Religion appeared in $16 \%$ (3) of cases and included the importance of preserving religious beliefs.

The remaining themes, i.e. distorted sense of justice (e.g. believing it is acceptable to murder certain offenders) and past drug use (i.e. offending to obtain access to a substance the perpetrator(s) was addicted to) appeared in only $5 \%$ (1) of cases.

\section{$\underline{\text { SORC and grounded analysis of incidents: Response (Behaviour) themes }}$}

This related to what occurred during the incidents. Themes included the aggression displayed, duration of crisis incident, and demands made. Regarding each theme, in rank order:

Aggression displayed was noted in 89\% (17) of incidents and included physical aggression (with no weapon: $\mathrm{n}=10)$, sexual aggression $(\mathrm{n}=1)$, self-injuring $(\mathrm{n}=1)$, verbal aggression $(\mathrm{n}=2)$, murder of a hostage $(n=3)$, forcing hostages to wear their prison attire $(n=1)$ and/or taking their possessions $(n=4)$. 
Duration of crisis incident was broken down into resolution in less than six hours $(\mathrm{n}=7)$ and over six hours $(\mathrm{n}=10)$, with two incidents not recording this.

Demands made appeared in $16 \%(\mathrm{n}=3)$ of the incidents, which included asking for fast food and asking to be killed by the authorities.

$\underline{\text { SORC and grounded analysis of incidents: Consequent (Reinforcer) themes }}$

Obtaining a reward was identified in all incidences and included gaining freedom or control over a victim $(\mathrm{n}=19)$, taking control away from those in authority $(\mathrm{n}=8)$, receiving encouragement from co-actors $(n=10)$, obtaining sexual gratification $(n=3)$ and experiencing a sense of redemption (i.e. belief in the act being righteous, $n=1$ ).

\section{Riot incidents}

\section{$\underline{\text { SORC and grounded analysis of incidents: Antecedent themes }}$}

Open coding was again conducted to identify all themes. Four themes were identified under antecedents: feeling negative, feeling rights have been violated, little resistance, and peer support. Regarding each theme, in rank order:

Feeling rights have been violated appeared in all instances and included feeling that rules are unfair and do not account for their rights, further reporting an absence of privacy and an unacceptable amount of living space. 
Support from peers appeared in all instances and included working with those with the same goal.

Feeling negative appeared in $83 \%$ (5) of instances and included feeling angry, wronged, lied to by authorities, feelings of injustice and dislike, desperation, and feeling they are not rewarded for compliance.

Little resistance appeared in $67 \%$ (4) of instances and related to there not being insufficient staff to prevent a riot.

$\underline{\text { SORC and grounded analysis of incidents: Background (Organism) themes }}$

Two themes were identified; beliefs that violence is acceptable and living in a stressful environment. Regarding each:

A belief that violence was acceptable appeared in $83 \%$ (5) instances and included retaliation beliefs connected to seeing others assault inmates and feeling unsafe in the environment and viewing violence as a solution.

Living in a stressful environment focused on placement in conditions of security and appeared in all instances. 
$\underline{\text { SORC and grounded analysis of incidents: Response (Behaviour) themes }}$

This included one core theme identified in $83 \%$ of instances, namely using aggression during the commission of a riot. This included causing damage to prison property and attacking others, including with a weapon.

$\underline{\text { SORC and grounded analysis of incidents: Consequent (Reinforcer) themes }}$

Obtaining a reward was identified in all incidents and included gaining freedom/control, being seen to destroy symbols of authority, and receiving encouragement from co-peers involved.

\section{Overall functions (motivations) for hostage taking and riot incidents}

The SORC and Grounded Theory analysis identified the following function themes for the hostage taking and riot situations respectively.

\section{$\underline{\text { Hostage taking }}$}

More than one function per incident was indicated. The following themes were identified:

- To cause pain to another for their crimes.

- To inflict pain for enjoyment.

- To cause the release of those imprisoned elsewhere.

- To solve a problem/manage stress.

- To remove negative emotions. 
- To remove/lessen feelings of injustice.

- To manage feelings of boredom.

- To demonstrate physical dominance over another.

- To overpower someone in authority.

- To allow a sense of freedom of action (and in some instances to experience pleasure as a result).

- To secure contact with a victim in a sealed situation.

- To secure support from other prisoners.

- To effect removal from stressful environment.

- For vengeance.

- To promote positive emotions.

- To allow negotiation with those in authority.

- To demonstrate a drive for serious action.

- To try to facilitate their own escape.

- To communicate negative feelings towards those in authority.

- To remove power from those in authority.

$\underline{\text { Riots }}$

Again, more than one function per incident could be indicated, with the following functions noted:

- To gain revenge towards those in a position of authority.

- To remove power from those in authority.

- To secure some degree of freedom within the environment. 
- To gain freedom/reduce control from authority.

- To gain control over the environment.

- To reduce stress.

- To retain rights that were perceived to be violated.

\section{Discussion}

These preliminary findings demonstrated how hostage incidents primarily included a single hostage. Triggers for both hostage taking and riots shared similarities, with background factors in relation to violence-supportive beliefs and being in a stressful environment also shared. The public reporting of both hostage taking and riots noted positive reinforcement in the form of gains but did not specifically describe negative reinforcement.

Triggers for the reported incidents focused on negative feelings (e.g. perceived injustice, negative emotions) and peer support for action. For both hostage taking and riots there was a clear environmental factor indicated in the form of opportunity to access a victim (hostage taking) and insufficient staff to prevent an action (riots), with both incidents noting support from

peers in the setting as further important. It would appear therefore that incidents are a combination of intrinsic factors (i.e. internal feelings and beliefs) and external circumstances (i.e. opportunity and supportive peer group). The intrinsic factors noted appear consistent with prior research indicating the importance of emotions and beliefs (e.g. Vollm et al, 2015; Vecchi et al, 2005; Mailloux \& Serin, 2003; Cooke et al, 1990), and supportive of the prediction that triggers would include negative emotions, such as frustration and anger (particularly for hostage taking).

However, the inclusion of external factors is not one readily identified in the literature, although there is recognition of this increasingly, such as research into riots (Boin \& Rattray, 
2014). It could be proposed that whereas focus on the minimisation of aggravating external factors might be part of routine management for preventing incidents, it is the management of the internal states and the willingness of a peer group to support that perhaps require further consideration. This would seem consistent with research suggesting that poor coping is a factor that could drive the decision to commit/become actively involved in a crisis-incident (e.g. Ireland et al, 2015; Hatcher et al, 1998; McMains, 1993), but the suggestion of focusing on the wider peer group and their willingness to support a potential incident is a novel one. Underpinning this is also the importance of exploring beliefs supporting violence use, which appeared evidenced in both hostage taking and riots when background factors were considered. It cannot be assumed, however, that the existence of such beliefs are simply consistent with general offence-supportive beliefs and thus should be present in all those with an offending history since only a small proportion of prisoners actually enact crisis incidents (Hatcher et al, 1998; Phillips, 2001). Rather, the origins of beliefs supporting the use of violence in this manner is a variable worthy of future study and one that should explore the existence of normative beliefs (i.e. beliefs held that an individual considers other to hold, without proven evidence), since such beliefs are known to promote violence (Ireland, 2018).

There was also evidence of the majority of incidents (riots and hostage taking) using violence during an incident, which has been noted in previous research to be associated with highly emotive states (e.g. Yokota et al, 2004). This is unsurprising considering the role of negative emotions and events as triggering factors for some incidents. Nonetheless, there were a proportion of hostage taking incidents $(11 \%)$ and riots $(17 \%)$ that did not demonstrate aggression during incidents. This is acknowledged to represent only a small sample but does highlight a question in relation to what is distinct about those incidents where violence is not used during. It is an area that research is yet to consider and yet valuable since it could identify protective factors relating to harm minimisation. 
Importantly, however, the question as to whether or not a crisis incident is in fact poor coping remains unclear. It cannot be assumed, for example, that a decision to engage in a crisis incident is necessarily because coping is maladaptive. Rather, the 'success' of such incidents might not be in their success as judged by external standards (e.g. achieving a goal such as escape or other demands) but by internal standards where an individual feels they are being heard and enacting some degree of control over their environment. This would seem supported by the range of functions indicated, where communicating, placing control on the power of those in authority, and gaining some degree of freedom were all indicated. Regardless of the external evaluation of the success of a crisis incident, it could be suggested that the incident and the choice therefore to engage in it, has met with success, thereby reinforcing the likely future use of such actions. The evaluation of external and internal perceived success of an incident has not, however, yet been considered and is a likely valuable avenue for future study.

Indeed, regarding the likely reinforcers of incidents (i.e. consequences likely to promote future use of the behaviour), only positive reinforcement was acknowledged, which did not support the prediction that such incidents could be reinforced by both negative and positive reinforcement (Verma, 2007). This finding could certainly represent an artefact of the method used (i.e. public reporting). However, even a review of the functions suggested from the SORC and Grounded Theory analysis suggests that motivations were dominated by gains (e.g. to cause another pain, to solve a problem, to secure contact, to communicate etc.) as opposed to causing the removal of an unpleasant state (e.g. to remove negative emotions: negative reinforcement). This does fit with previous research that has noted incidents to be motivated by perceived likely gains (e.g. Hatcher et al, 1998). Negative reinforcement is, nonetheless, a difficult variable to ascertain from collateral information alone and arguably benefits more from a detailed exploration of the internal and external consequences of an action with the perpetrator(s) directly. 
The functions indicated were broad for both hostage taking and riots. The suggestion that such incidents lack motivation is clearly not indicated by the current results (e.g. Yun \& Roth, 2008; Wilson \& Smith, 2000). The functions were the same for riots and hostage taking but the latter produced a wider range of functions, likely a result of the larger sample. Nevertheless, hostage taking did appear to capture motivations underpinned by negative emotions whereas riots did not, other than an indication of rioting to manage stress. Overall, this preliminary analysis suggests that riots were driven by a need to communicate, to secure power, rights, control and/or freedom whereas for hostage taking these functions were extended beyond this to capture the removal of negative emotions, to inflict pain, to punish/gain revenge, to effect a release, to manage boredom, and to promote positive emotions. Regardless of the difference in number of incidents sampled (i.e. 19 hostage taking versus six riots) there did appear a qualitative difference between them worthy of at least some mention.

The study is not, however, free from limitations. It is a preliminary study dependent on the quality of public reporting and availability of the same. It does not, for example, allow any means of accessing after incident reports not in the public domain, which no doubt would contain more detail. It also does not capture the development of associations between individuals and how this could impact incidents. Consequently, there was no means of extending the discussion to theories such as Differential Association Theory (Burgess \& Akers, 1966). There were also fewer riot incidents captured in comparison to hostage taking incidents, but even the latter was limited in incident number. There was also insufficient information considering wider external factors to examine the application of models such as the Threshold Model (Boin \& Rattray, 2004).

It was also not possible to control for the quality of the public reporting. However, using a functional analysis approach (SORC) to capture data and then using Grounded Theory to analyse themes was utilised as a means of ensuring that the data that was available was 
investigated as thoroughly as possible. The results also indicate the importance of further studying this area, not just the value in identifying triggers, reinforcers and functions but also by indicating gaps in the research field. The study did not, for example, identify a range of negative reinforcers for incidents. As noted, this could be an example of the data available but it also suggests that such reinforcers and their presence or otherwise requires examination using a different method in order to confirm this.

In addition, the factors protecting against crisis incidents were not indicated and could represent a further area of study. Identifying the factors that protect not just against the commission of a crisis incident but also the minimisation of harm once it commences, is a worthy area for study. Further extending the research to the full range of crisis incidents (e.g. roof-top protests, barricades) would also enhance the knowledge base, although these are likely to be informed by directly acquired incident records at the secure sites as opposed to using public reports alone.

\section{References}

Birch, P., Ozanne, R., Ireland, J. L. (2017). Examining the portrayal of homophobic and nonhomophobic aggression in print media through an integrated grounded behavioural linguistic inquiry (IGBLI) approach. Journal of Forensic Practice, 19: 239 - 244. Boin, A., \& Rattray, W. A. (2004). Understanding prison riots: Towards a threshold theory. Punishment \& Society, 6(1), 47-65.

Boin, A., Rattray, W. A. (2004). Understanding prison riots: Towards a threshold theory. Punishment \& Society, 6: 47-65

Burgess, R. L., Akers, R. L. (1966). A differential association-reinforcement theory of criminal behavior. Social problems, 14: 128-147 
Cooke, D. J., Baldwin, P. J., Howison, J. (1990). 'Hostage taking in prisons'. In D. J. Cooke, P. J. Baldwin, J. Howison (Eds.). Psychology in Prisons (pp. 112-122). New York: Routledge.

Feldman, T. (2001). Characteristics of hostage and barricade incidents: implications for negotiation strategies and training. Journal of Police Crisis Negotiations, 1: 3-32.

Furr, K. D. (1994). Hostage taking and Sexual Assault. Correctional Service of Canada: Ottawa, Ontario.

Glaser, B. M., Straus, A. (1967). The Discovery of Grounded Theory. Chicago, IL: Aldine.

Hatcher, C., Mohandie, K. Turner, J. Gelles, M. G. (1998). The role of the psychologist in crisis/hostage negotiations. Behavioural Science and the Law, 16: 455-472.

Hoffman, E. A. (2005). Dispute resolution in a worker cooperative: Formal procedures and procedural justice. Law \& Society Review, 39: 51-82.

Ireland, J. L. (2018). 'Individual assessments for aggression: Accounting for core factors' in J. L. Ireland, C. A. Ireland \& P. Birch (Eds.) Violent and Sexual Offenders: Assessment, Treatment and Management $2^{\text {nd }}$ Edition), Routledge: Taylor \& Francis.

Ireland, C. A., Halpin, L., Ireland, J. L. (2015). Exploring Individual Factors Associated with Critical Incidents in a Secure Psychiatric Setting: A Preliminary Study. Psychiatry, Psychology and Law, 22: 259-272.

Lee-Evans, J. M. (1994). 'Background to behavioural analysis', in M. McMurran and J. Hodge (Eds.). The Assessment of Criminal Behaviours of Clients in Secure Settings, (pp. 6 - 33), Jessica Kingsley Publishers: London.

Lindsay-Brisbin, J., DePrince, A. P., Welton-Mitchell, C. (2014). Missed opportunities: Newspaper reports of domestic violence. Journal of Aggression, Maltreatment \& Trauma, 23: 383-399. 
Mailloux, D. L., Serin, R. C. (2003). Sexual assaults during hostage takings and forcible confinements: Implications for practice. Sexual Abuse: A Journal of Research and Treatment, 15: $161-170$.

McMains, M. J. (1993). 'Psychologists' roles in hostage negotiations'. In J. T. Reese and J. M. Horn (Eds.), Police Psychology: Operational Assistance (pp. 281-309). Washington DC: Department of Justice.

Phillips, E. M. (2011). Violence research pain, suffering and humiliation: The systemization of violence in kidnapping for ransom. Journal of Aggression, Maltreatment \& Trauma, 20: 845869.

Schreiber, R. S., Stern, P. N. (2001). Using Grounded Theory in Nursing. New York, NY, USA: Springer Publishing Company.

Vecchi, G. M., Van Hasselt, V. B., Romano, S. J. (2005). Crisis (hostage) negotiation: current strategies and issues in high-risk conflict resolution. Aggression and Violent Behavior, 10: $533-551$.

Verma, A. (2007). Anatomy of riots: A situational crime prevention approach. Crime Prevention and Community Safety, 9: 201-221.

Völlm, B. A., Bickle, A., Gibbon, S. (2013). Incidents of hostage taking in an English high-secure hospital. Journal of Forensic Psychiatry \& Psychology, 24: 16-30.

Williams, S. (1995). Review of sexual assaults and forcible confinements. Ottawa, Ontario: Correctional Service of Canada.

Wilson, M., Smith, A. (2000). 'Rules and roles in terrorist hostage taking'. In Canter, D. \& Alison, L. (Eds.), The Social Psychology of Crime: Groups, Teams and Networks (pp. 129 51), Aldershot: Ashgate. 
Yokota, K., Iwami, H., Watanabe, K., Fujita, G., Watanabe, S. (2004). High risk factors of hostage barricade incidents in a Japanese sample. Journal of Investigative Psychology and Offender Profiling, 1: 139-151.

Yun, M., Roth, M. (2008). Terrorist hostage taking and kidnapping: Using script theory to predict the fate of a hostage. Studies in Conflict \& Terrorism, 31: 736-748. 
Table 1

Crisis incidents $(n=25)$ by country and type

\begin{tabular}{cccccc}
\hline Country & & \multicolumn{2}{c}{ Crisis Incident-Type } & Total \\
& Hostage & Barricade & Rooftop- & Riot & \\
& & & Protest & & \\
UK & 6 & 0 & 0 & 4 & $\mathbf{1 0}$ \\
US & 13 & 0 & 0 & 2 & $\mathbf{1 5}$ \\
\hline Total & $\mathbf{1 9}$ & $\mathbf{0}$ & $\mathbf{0}$ & $\mathbf{6}$ & $\mathbf{2 5}$ \\
\hline
\end{tabular}


Figure 1. Example of SORC data capture sheet (Riot)

\section{Antecedents}

Specific Triggers: Dislike of rules; small Intensity: Damage of cells/ prison wing.

confinement for long period, lack of outside time

Duration: 30 mins

freedom. Support from inmates.

External Conditions: Supported view from other prisoners. Not enough officers to prevent riot.

Internal Conditions: Anger.

Belief their greater numbers held advantage.

Cognitions: Opportunity - "Now or Never"

\section{Organism (background) variables}

Belief that rioting and aggressive behaviour are acceptable means of protest; harm to authority is valid.

History of being in stressful environments.

\section{Consequences}

Positive Reinforcement: Support from inmates.

Negative Reinforcement: Removal of stress 